\title{
LBBB masking the ECG changes of inferior wall infarction: a caution to be vigilant
}

\author{
Pritesh Parekh, Navin Agrawal, Apurva Vasavada, Mahesh Vinchurkar
}

Department of Cardiovascular Sciences Care Hospital, Surat, Gujarat, India

\section{Correspondence to} Dr Navin Agrawal, drnavinagrawal@gmail.com

Accepted 8 May 2014
CrossMark

To cite: Parekh $\mathrm{P}$, Agrawal N, Vasavada A, et al. BMJ Case Rep Published online: [please include Day Month Year] doi:10.1136/bcr-2014205095

\section{DESCRIPTION}

The occurrence of left bundle branch block (LBBB) is known to mask the ECG changes of anterior wall myocardial infarction (AWMI) because of the changes it causes in the ST-T segments of the precordial leads. The ECG changes of inferior wall infarction (IWMI) which affects the limb leads are usually unaffected by the intraventricular conduction abnormality caused by LBBB. The occurrence of an IWMI being completely masked by the presence of a pre-existent LBBB on the ECG is an important occurrence which needs to be highlighted and discussed. ${ }^{1-4}$

We present an interesting image of a middle aged man who presented to us with acute onset of severe chest pain with a window period of $3 \mathrm{~h}$. The presenting ECG was confusing as it showed changes of an LBBB with no changes in limb leads which would have suggested an infarction (figure 1). The conventional Sgarbossa criterion which needs to be satisfied to diagnose an AWMI in the presence of LBBB were not satisfied. ${ }^{13}$ The diagnosis of an IWMI was suspected on the basis of the echocardiogram performed which showed the occurrence of significant hypokinesia in the inferior and posterior wall territory (videos 1 and 2). The angiogram revealed thrombotic occlusion of proximal right coronary artery which confirmed our diagnosis of an inferior wall infarction. The patient subsequently underwent successful primary angioplasty to the occluded right coronary artery. The lesion was soft to cross with a wire as is expected in case of acute thrombotic occlusion (figures 2 and 3, videos 3 and 4).The symptoms subsided after the procedure although there was no change in the ECG which still showed LBBB morphology (figure 4).

This case highlights the importance of this variation in ECG and also highlights the role of echocardiography and angiography in facilitating the correct diagnosis. This case stresses the fact that in patients with pre-existing LBBB more reliance should be placed on other modalities to diagnose an infarct to enable the appropriate treatment to be administered without wasting crucial time to salvage the threatened myocardium.

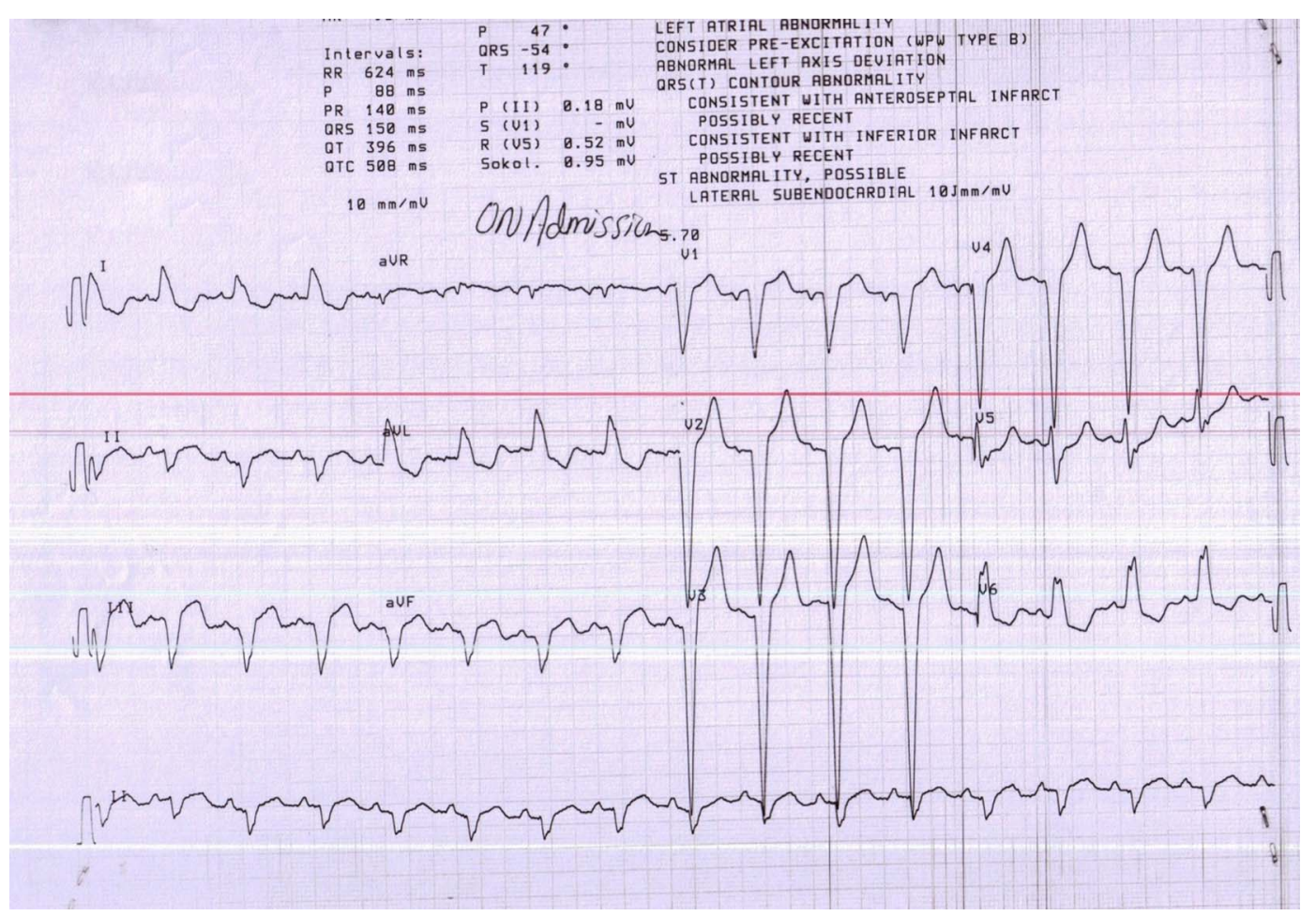

Figure 1 Presentation ECG of the patient showing changes of left bundle branch block on the ECG but no changes to suggest an inferior wall infarction. 


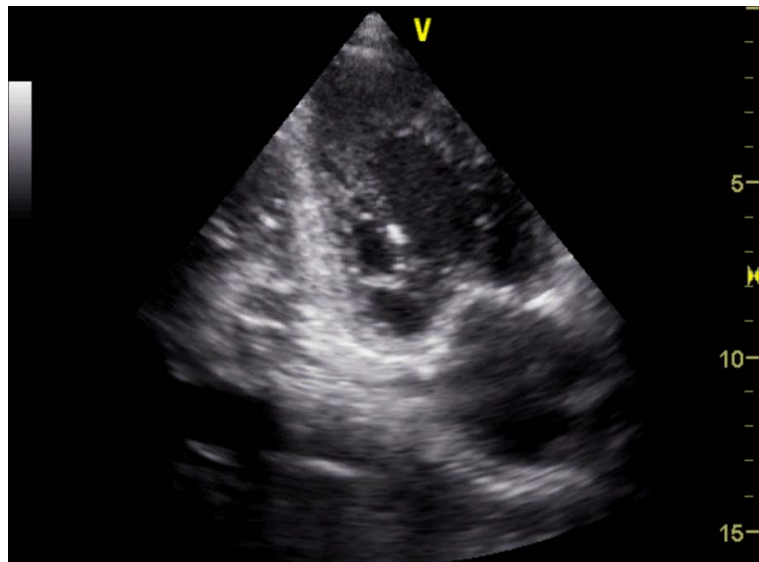

Video 1 Apical two chambered view showing significant inferior wall hypokinesia.

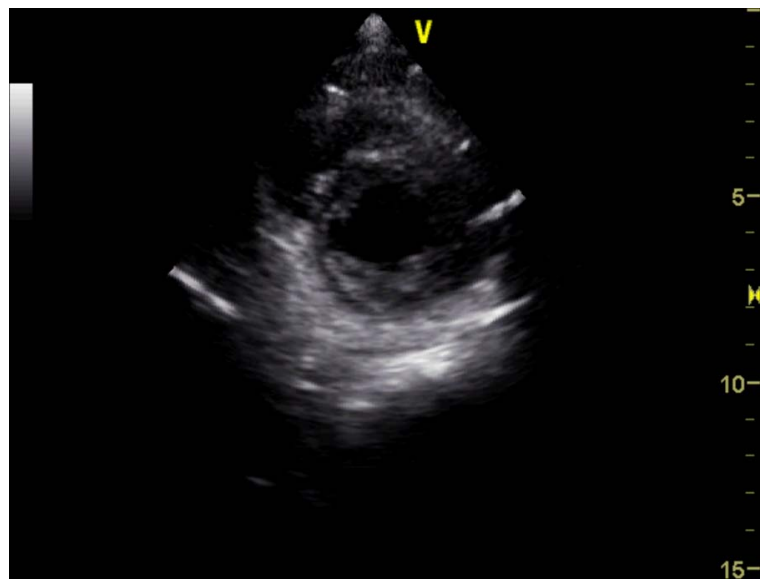

Video 2 Parasternal short axis view showing inferior wall hypokinesia.

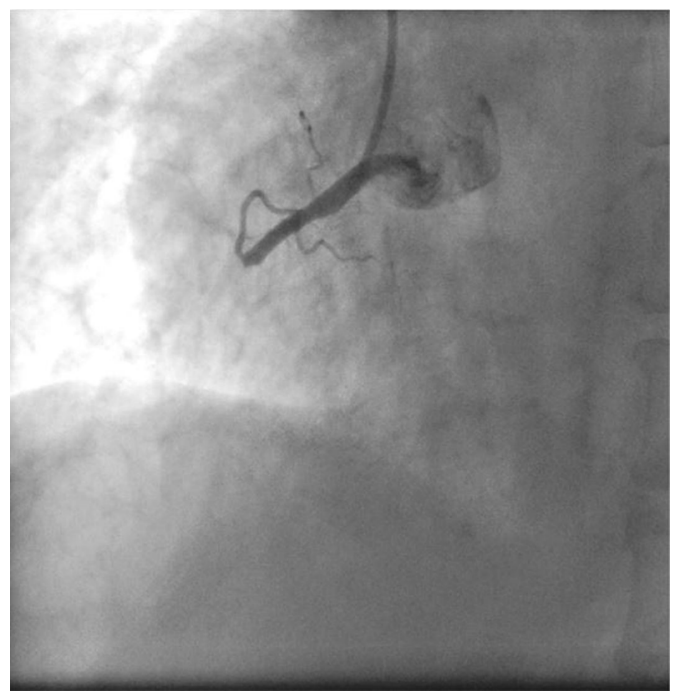

Figure 2 Left anterior oblique view showing acute thrombotic occlusion of the proximal right coronary artery.

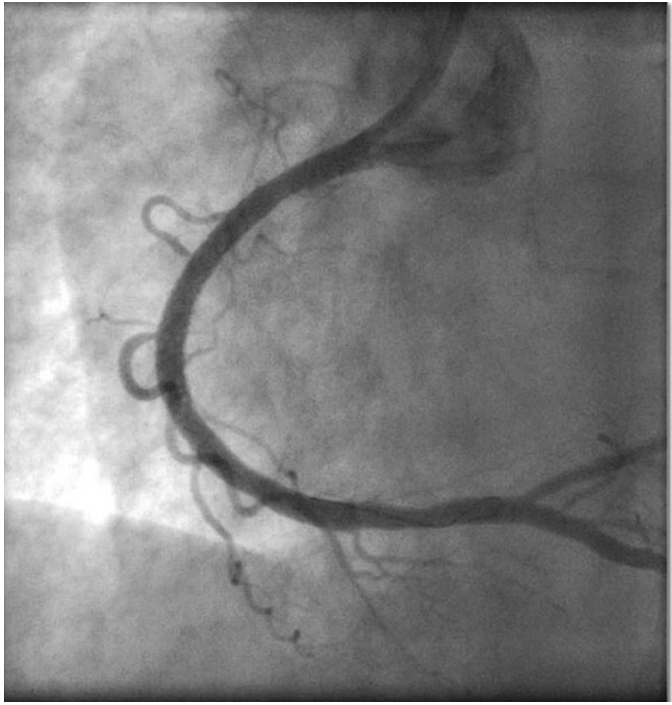

Figure 3 Left anterior oblique view showing successful revascularisation of the right coronary artery after the primary angioplasty procedure.

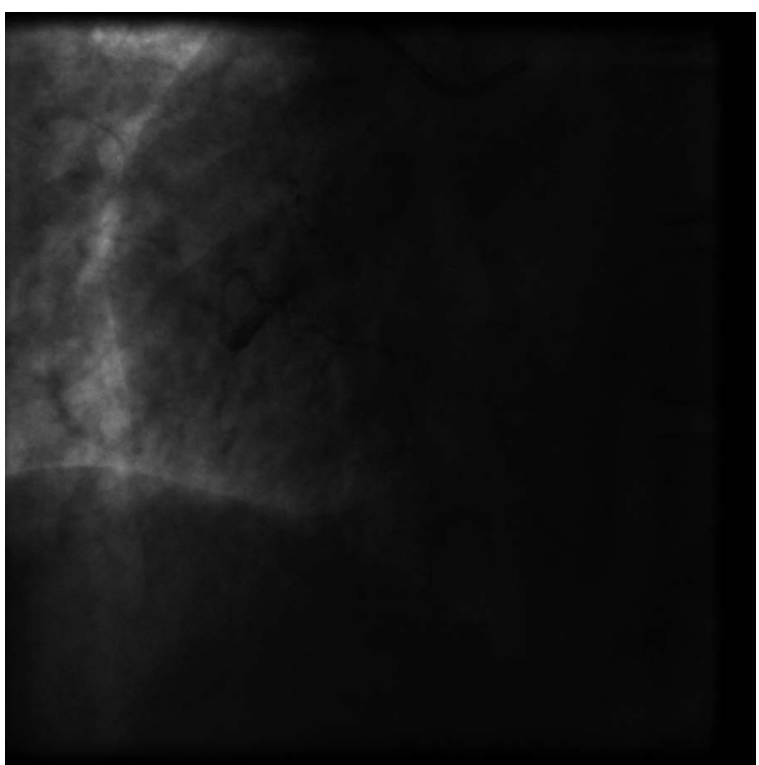

Video 3 LAO view showing acute thrombotic occlusion of the proximal RCA.

\section{Learning points}

- Pre-existent left bundle branch block (LBBB) can even mask the changes of an inferior wall myocardial infarction as it does for an anterior wall infarction.

- This finding should be brought to light and discussed for the benefit of the practitioners and physicians dealing with such cases to enable appropriate and timely management which could prove lifesaving in such high-risk patients.

- This case illustrates the value of an echocardiogram and a diagnostic coronary angiogram which helps in an immediate diagnosis and facilitates early administration of appropriate treatment to salvage the threatened myocardium. 


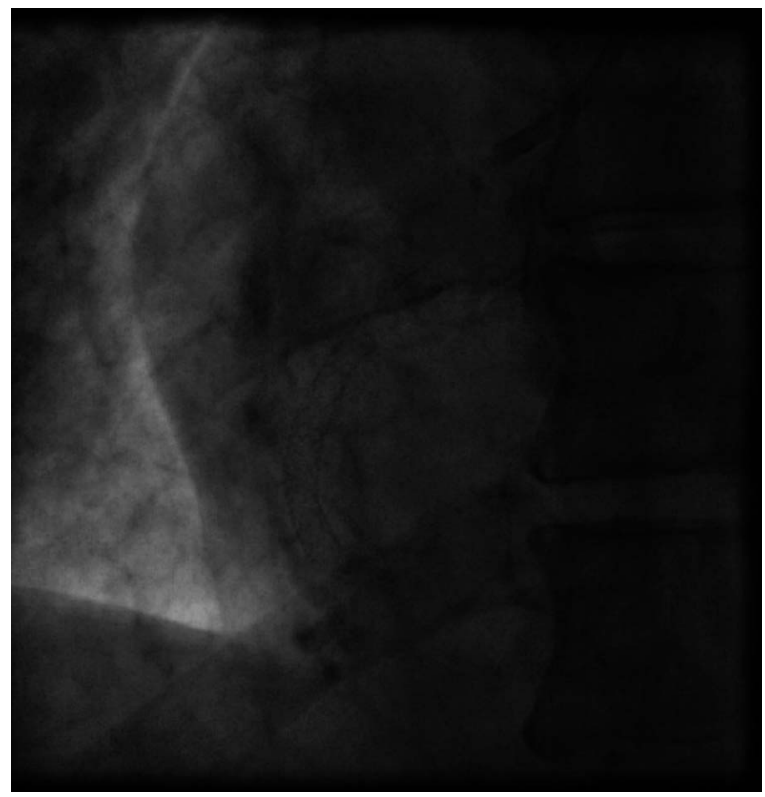

Competing interests None.

Patient consent Obtained.

Provenance and peer review Not commissioned; externally peer reviewed.

\section{REFERENCES}

1 Sgarbossa EB, Pinski SL, Barbagelata A, et al. Electrocardiographic diagnosis of evolving acute myocardial infarction in the presence of left bundle-branch block. N Engl J Med 1996;334:481-7.

2 Al-Faleh $\mathrm{H}$, Fu Y, Wagner G, et al. Unraveling the spectrum of left bundle branch block in acute myocardial infarction: Insights from the Assessment of the Safety and Efficacy of a New Thrombolytic (ASSENT 2 and 3) trials. Am Heart J 2006;151:10-15.

3 Tabas JA, Rodriguez RM, Seligman HK, et al. Electrocardiographic criteria for detecting acute myocardial infarction in patients with left bundle branch block: a meta-analysis. Ann Emerg Med 2008;52:329-36.e1.

4 Sgarbossa EB. Value of the ECG in suspected acute myocardial infarction with left bundle branch block. J Electrocardiol 2000;(33 Suppl):87-92.

Video 4 LAO view showing successful revascularisation of the RCA after the primary.

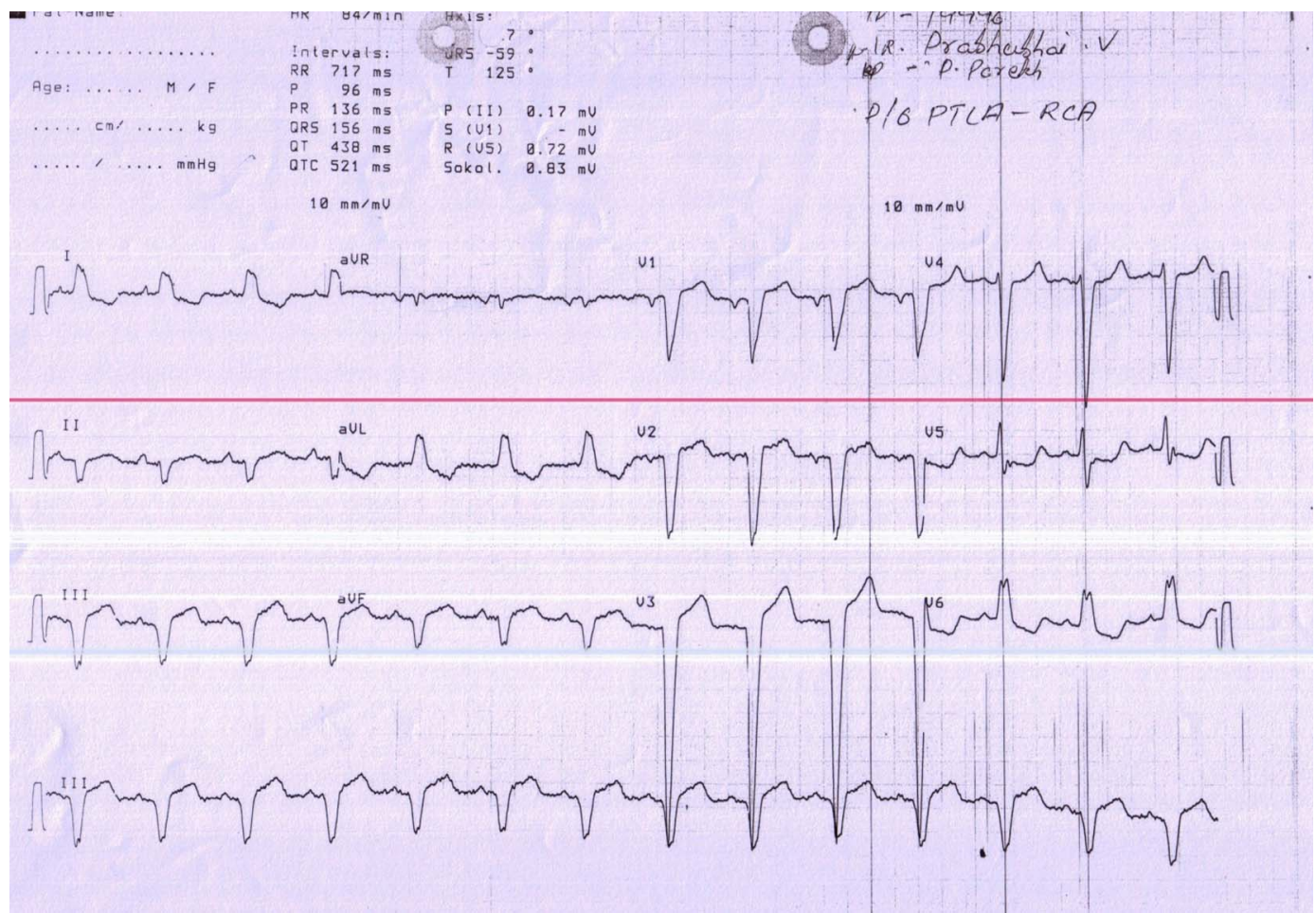

Figure 4 The postangioplasty ECG showing the same left bundle branch block pattern without significant ST-T changes. 


\section{Images in...}

Copyright 2014 BMJ Publishing Group. All rights reserved. For permission to reuse any of this content visit http://group.bmj.com/group/rights-licensing/permissions.

BMJ Case Report Fellows may re-use this article for personal use and teaching without any further permission.

Become a Fellow of BMJ Case Reports today and you can:

- Submit as many cases as you like

- Enjoy fast sympathetic peer review and rapid publication of accepted articles

- Access all the published articles

- Re-use any of the published material for personal use and teaching without further permission

For information on Institutional Fellowships contact consortiasales@bmjgroup.com

Visit casereports.bmj.com for more articles like this and to become a Fellow 